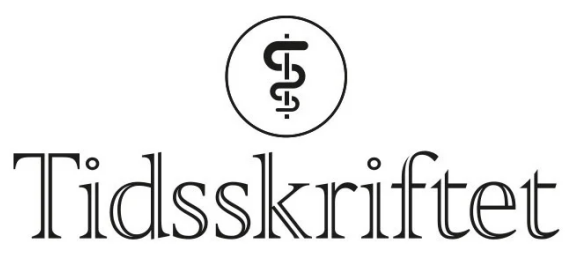

DEN NORSKE LEGEFORENING

\title{
Hva menes med «sykdommens alvorlighetsgrad»?
}

KRONIKK

\section{JAN ABEL OLSEN}

Jan Abel Olsen (f. 1954) er siviløkonom, dr.philos., professor i helseøkonomi ved Universitetet i Tromsø og forsker ved Nasjonalt kunnskapssenter for helsetjenesten. Forfatter har fylt ut ICMJE-skjemaet og oppgir ingen interessekonflikter. Email: jan.abel.olsen@uit.no

\section{Begrepet «sykdommens alvorlighetsgrad» forekommer} i litteraturen med fire ulike meningsinnhold. Denne begrepsmessige forvirringen har helsepolitisk betydning, fordi vi i Norge har et uttalt mål om å ta hensyn til alvorlighetsgrad ved prioriteringer. Forskjellene mellom de ulike definisjonene av begrepet kan illustreres i en figur. Gjennom noen talleksempler kan vi se hvordan ulike meningsinnhold gir ulike prioriteringsimplikasjoner.

Siden det første prioriteringsutvalget (1) har begrepet «sykdommens alvorlighetsgrad» stått sentralt i diskusjoner om norske prioriteringsretningslinjer. Prinsippene fra det andre prioriteringsutvalget (Lønning II-utvalget) er videreført i prioriteringsforskriften, der alvorlighetsgrad er beskrevet som "prognosetap med hensyn til livslengde eller ikke ubetydelig nedsatt livskvalitet dersom helsehjelpen utsettes» (2) $)$. Dette likner en definisjon i veilederen for Samfunnsøkonomiske analyser i helsesektoren fra Helsedirektoratet: «Grad av helsetap i forhold til gjennomsnittlig, god helse» (3). Problemet er at denne definisjonen står i motsetning til andre forståelser av begrepet.

Noen bruker begrepet «sykdommens alvorlighetsgrad» om grad av dårlig helsetilstand, noen bruker det om kort gjenværende levetid, noen tenker at det dreier seg om en dårlig prognose, mens andre mener det dreier seg om hvor stort helsetap en sykdom innebærer. Alvorlighetsgrad har altså fire ulike meningsinnhold.

Denne begrepsforvirringen finnes også i engelskspråklig faglitteratur, der «severity» er blitt brukt på (minst) fire ulike måter. Likevel, felles for de ulike forståelsene - både på norsk og engelsk - synes å være at det gjerne brukes med referanse til et avvik fra en normal forventet (mengde) helse, m.a.o. den helsetilstand folk flest i vedkommende aldersgruppe har, og den forventede gjenværende levetid som gjelder for aldersgruppen. 
Denne språklige forvirringen er ikke bare et tema for pedanter og folk med interesse for ordkløveri. Begrepsforvirringen har nemlig helsepolitisk betydning, fordi vi i Norge har som mål å ta hensyn til alvorlighetsgrad ved prioriteringer, dvs. at pasienter som har sykdommer med høy alvorlighetsgrad, skal prioriteres foran dem med lavere alvorlighet. Hvordan man velger å måle grad av alvorlighet, får derfor betydning for hvordan man prioriterer.

Hensikten med denne artikkelen er først å oppklare en begrepsforvirring. Rammen for diskusjonen vil være en enkel figur som viser hvordan sykdom påvirker pasientens helsejusterte forventede levetid. Med henvisning til denne figuren vil jeg vise hva de ulike definisjoner av alvorlighet sikter til. Deretter vil jeg vise motsetningene i

prioriteringsimplikasjonene som følger av de ulike begrepsforståelsene. Sakens kjerne er at man prioriterer ut fra et mål om å redusere en type helseulikhet: Dersom man er opptatt av helsesituasjonen uten behandling, vil det avspeile en målsetting om å redusere ulikheter i folks gjenværende helse. Dersom man i stedet er opptatt av helsetapets størrelse, vil det kunne reflektere et ønske om å redusere ulikheter i den samlede helse. Gjennom talleksempler skal jeg vise hvordan ulike meningsinnhold gir ulike prioriteringer.

\section{Helsejustert forventet levetid}

Vår forventede «mengde» helse kan måles langs to dimensjoner: kvantitet som forventet levetid (LE), og kvalitet som uttrykk for helsetilstanden (H) på hvert tidspunkt.

Helsetilstanden, eller den helserelaterte livskvaliteten, måles gjerne på en o-1-skala fra død til best tenkelige helsetilstand.

Denne helsejusterte forventede levetid kan uttrykkes i form av et antall kvalitetsjusterte leveår (quality-adjusted life years, QALY). Selv om QALY vanligvis brukes for å måle helsegevinster, kan denne telleenheten i prinsippet også brukes til å måle andre "helsemengder». Et leveår med best tenkelige helse er 1 QALY, ett år med halvgod helse blir en o,5 QALY, og tilsvarende blir to år med halvgod helse 1 QALY. Slik kvalitetsjustering - eller helsejustering - av forventet levetid ligger til grunn for beregning av vår helsejusterte forventede levealder (quality-adjusted life expectancy; (QALE) eller health-adjusted life expectancy (HALE)). Forventet levealder i Norge er 81 år, mens vår helsejusterte forventede levetid er 73 år (4). Forskjellen mellom forventet levetid (LE) og helsejustert levetid (QALE) avhenger av hvor dårlig helsen er gjennom livet.

Figur 1 illustrerer en antatt profil på gjennomsnittsnordmannens forventede helse, uttrykt ved helsejustert forventet levetid. Etter en viss alder setter det biologiske forfallet ubønnhørlig inn, uttrykt ved fall i den helserelaterte livskvaliteten, $\mathrm{H}$.

Figur 1 Helsejustert forventet levetid (quality-adjusted life expectancy, QALE). $\mathrm{H}=$ helserelatert livskvalitet, $\mathrm{LE}=\ldots$

Figur 1 Helsejustert forventet levetid (quality-adjusted life expectancy, QALE). $\mathrm{H}=$ helserelatert livskvalitet, $\mathrm{LE}=$ forventet levetid, $(\mathrm{H}=1)=$ best tenkelig helsetilstand

Ens helsejusterte forventede levetid varierer avhengig av arv, miljø og atferd. Kvinner lever ca. $6 \%$ lenger enn menn, ikke-røykere lever ca. 8 \% lenger enn røykere, og de høyeste sosiale lag ca. $10 \%$ lenger enn de laveste sosiale lag.

\section{Når sykdom inntreffer}

Når sykdom plutselig inntreffer, blir QALE splittet i fire "helsemengder»: tidligere helse (målt ved hvor lenge man allerede har levd og i hvor god helsetilstand), gjenværende helse uten behandling (prognose), gevinst som følge av behandling samt (netto) helsetap dersom behandlingen ikke er $100 \%$ effektiv. 
Selv om den totale QALE er gitt, vil disse fire helsemengdene selvsagt variere fordi sykdommer inntreffer ved ulik alder, sykdommer har ulik prognose uten behandling, effekten av behandling varierer, og når behandlingen ikke er fullt ut kurerende, vil det nødvendigvis bli et helsetap. Logisk sett er størrelsen på helsetapet en residual som avhenger av pasientens alder, prognosen uten behandling og hvor effektiv behandlingen er.

Figur 2 illustrerer hva som skjer med QALE når sykdom inntreffer på tidspunkt $\mathrm{T}_{\mathrm{A}}$ : A viser hvor mye helse man har hittil. Dersom vi for enkelhets skyld antar at helsetilstand hele tiden har vært best tenkelig $(\mathrm{H}=1)$, vil nettopp denne tidligere mengde QALY man har hatt tilsvare deres alder, A. For eksempel vil en 50 år gammel mann uten tidligere sykdom eller plager ha hatt 50 QALY. Dersom han i ti av disse årene hadde nedsatt helsetilstand til o,5 ville han hatt fem færre, altså 45 QALY.

Figur 2 Fra helsejustert forventet levetid til fire «helsemengder» $\mathrm{H}=$ helserelatert livskvalitet, $(\mathrm{H}=1)=$ best tenkelig...

Figur $\mathbf{2}$ Fra helsejustert forventet levetid til fire «helsemengder» $\mathrm{H}=$ helserelatert livskvalitet, $(\mathrm{H}=1)=$ best tenkelig helsetilstand, $\mathrm{hU}=$ helsetilstand ubehandlet, $\mathrm{TA}=$ sykdom inntreffer på tidspunkt $\mathrm{A}$ (A viser hvor mye helse man har hittil), $\mathrm{TP}$ = prognose uten behandling, $\mathrm{TG}=$ gevinst med behandling, $(\mathrm{TP}-\mathrm{TA})=$ gjenværende levetid uten behandling, $\mathrm{LE}=$ forventet levetid

Konsekvensen av sykdom er et fall i helserelatert livskvalitet og/eller redusert forventet gjenværende livslengde. P er prognosen, eller gjenværende helse uten behandling. $G$ er gevinsten, eller vunnet helse med behandling (QALY-gevinst i kostnad-effekt- analyser). Til slutt har vi det gjenværende (netto) helsetapet, $\mathrm{HT}_{\mathrm{N}}$, som skyldes at eksisterende behandlinger ikke fullt ut kan kompensere for sykdomsbyrden. Altså:

$\mathrm{QALE}=\mathrm{A}+\mathrm{P}+\mathrm{G}+\mathrm{HT}_{\mathrm{N}}$

Denne oppsplittingen av QALE kan lett utvides til å skille mellom gevinster fra eksisterende behandling og fra ny behandling. Men fordi man ved en beslutning om å tilby en ny behandling nettopp er opptatt av den inkrementelle gevinsten, er gevinsten fra eksisterende behandling for enkelhetsskyld her inkludert i hva som uttrykkes i form av gjenværende helse uten (den nye) behandling.

Det nyttige med denne figuren er at den kan brukes til å illustrere hvordan enhver tenkelig sykdom som inntreffer i en pasientgruppe, vil splitte deres QALE i de fire ulike helsemengdene. Noen sykdommer innebærer redusert helserelatert livskvalitet, noen gir forkortet gjenværende livslengde, mens andre innebærer kort gjenværende levetid. Men hvilken har da størst alvorlighetsgrad?

\section{Motstridende begrepsbruk}

På engelsk brukes «severity of illness» eller «severity of disease» om sykdommens alvorlighetsgrad. Den klart mest vanlige bruken av begrepet i litteraturen er at det sikter til helsetilstanden ubehandlet på et gitt tidspunkt, altså $\mathrm{h}_{\mathrm{U}}$ i figur 2 (5)-(11). Særlig gjelder dette Nords mange sentrale - og meget siterte - arbeider knyttet til transformasjon av helsetilstandsverdier, der en gitt grad av forbedring fra en alvorlig initial helsetilstand har

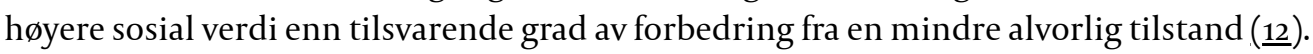

I stedet for den vertikale helsetilstanden er en annen bruk av begrepet med referanse til leveutsiktene ubehandlet, altså $\left(T_{P}-T_{A}\right)$ i figur 2. Denne forståelsen finner vi også blant norske forfattere (13,14). En tredje bruk av begrepet er med referanse til prognosen uten behandling, altså det skraverte feltet i figuren. Denne tar altså hensyn til både helsetilstanden og den gjenværende levetiden ubehandlet (15)-(17.). 
En siste forståelse, i sterk kontrast til de foregående, er å bruke begrepet om størrelsen på helsetapet, eller sykdomsbyrden ubehandlet, som i figur 2 er illustrert med summen av feltene Gevinst og (Netto) helsetap (묘). Denne forståelsen synes å være den man sikter til i alvorlighetskriteriet i prioriteringsforskriften: «Pasienten har rett til nødvendig helsehjelp (... ) når: pasienten har et visst prognosetap med hensyn til livslengde eller ikke ubetydelig nedsatt livskvalitet dersom helsehjelpen utsettes» (2).

Disse motstridende forståelsene av begrepet har selvsagt implikasjoner for hva som menes når man sier at man skal ta hensyn til sykdommens alvorlighet ved prioriteringer.

\section{Prioriteringsimplikasjoner}

Når alvorlighetsgrad sikter til grad av dårlig helsetilstand ubehandlet ( $\mathrm{h}_{\mathrm{U}}$ i figur 2 ), innebærer det at pasienter med størst nedsatt helserelatert livskvalitet prioriteres, m.a.o. at en helsetilstandsendring skal tillegges større vekt desto lavere utgangstilstanden er. Legg merke til at denne vektingen er varighetsuavhengig, dvs. at den ikke tar hensyn til alder eller tapte leveår.

Når alvorlighetsgrad sikter til hvor kort gjenværende levetid uten behandling er $\left(\left(T_{P}-T_{A}\right)\right.$ i figur 2), følger det at man skal prioritere de som har kortest restlevetid. I Storbritannia har

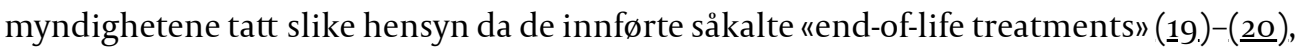
der grensen ble satt ved om pasienter har kortere forventet restlevetid enn to år. Igjen er denne vektingen uavhengig av alder og tapte leveår. Om en 2o-åring har tre år igjen ubehandlet, mens en 7o-åring har to år igjen ubehandlet, vil altså den eldste prioriteres.

Prognosen uten behandling beskrives både med hvor redusert helsetilstanden er og hvor kort gjenværende levetid er (det skraverte arealet i figur 2). For eksempel vil en forventet restlevetid på to år med halvgod helse innebære en gjenværende helse ubehandlet tilsvarende 1 QALY. Slike prognoser gir assosiasjoner til terminale kreftpasienter. Implikasjonen av den tredje forståelsen av sykdommens alvorlighetsgrad er at desto mindre gjenværende helse pasienten har ubehandlet, desto høyere skal han/hun prioriteres. Igjen er dette prinsippet uavhengig av pasientens alder og helsetap. Dersom vi er enige om at både helsetilstanden og dens varighet er relevant å ta hensyn til, kan vi forenkle ved å si at de første to forståelsene av begrepet inngår i denne tredje, dvs. at prognosen uten behandling uttrykker sykdommens alvorlighetsgrad.

Den fjerde forståelsen av begrepet er å prioritere i henhold til hvor stort det potensielle helsetapet er. Siden helsetapet nødvendigvis vil avhenge av alder, følger det at en gammel pasient aldri kan kalles alvorlig syk. Prioritering ut fra størrelsen på helsetapet er m.a.o. en indirekte måte å si at man skal prioritere avhengig av alder.

Vi står altså igjen med hvorvidt prognose eller summen av gevinst og (netto) helsetap skal være det operasjonelle mål på sykdommens alvorlighetsgrad (fig 2): Jo mindre P, desto mer alvorlig, eller jo større $\left(\mathrm{G}+\mathrm{HT}_{\mathrm{N}}\right)$, desto mer alvorlig. En ting er den opplagte forvirringen forbundet med motstridende meningsinnhold i et begrep, noe annet er hvilken prioriteringsrelevans hver av de fire størrelsene måtte ha. Dette dreier seg i bunn og grunn

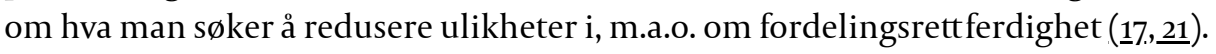

\section{Likhet i hva?}

I de følgende parvise sammenlikningene uttrykkes alle de fire størrelsene i form av QALYs, der summen tilsvarer den helsejusterte forventede levetid før sykdommen inntraff, jfr. likningen ovenfor: $\mathrm{QALE}=\mathrm{A}+\mathrm{P}+\mathrm{G}+\mathrm{HT}_{\mathrm{N}}$. I hvert eksempel er gevinstene, $\mathrm{G}$, like stor. Spørsmålet er hvorvidt ulikheter i de øvrige helsemengder gjør at den ene pasienten skal prioriteres foran den andre, og med hvilken begrunnelse. 
Begrunnelsen for å ta hensyn til ulikheter i prognose er barmhjertighet eller vår moralske

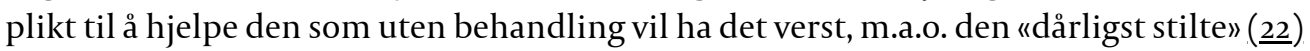
eller den mest akutt syke (rule of rescue) (23). Dette innebærer et mål om å redusere ulikheter i den gjenværende helse $(P+G)$. I det første eksemplet (tab 1) er gjenværende helse uten behandling ulik, mens den totale helse uten behandling $(\mathrm{A}+\mathrm{P})$ er lik. Det illustrerer forebygging versus behandling, f.eks. mild hypertensjon versus terminal kreft. Dersom vi anser prognosen isolert sett å være prioriteringsrelevant, følger det at vi vil prioritere person Ola, noe som samsvarer med de britiske «end of life»-retningslinjene (19.)-(므). Hvis vi i stedet er opptatt av å redusere ulikheter i helsetap, ser vi at det er like stort, og de to blir like prioriteringsverdige. Dette vil også gjelde om vi var opptatt av å redusere ulikheter i total helse uten behandling, fordi $(\mathrm{A}+\mathrm{P})$ er lik for begge pasienter.

\section{Tabell 1}

Talleksempel med ulik alder og prognose, lik gevinst og tap. QALE = helsejustert forventet levetid (quality-adjusted life expectancy)

\begin{tabular}{|lccccc|}
\hline & Alder & Prognose & Gevinst & Tap & QALE \\
\hline Per & 50 & 21 & 1 & 3 & 75 \\
\hline Ola & 70 & 1 & 1 & 3 & 75 \\
\hline
\end{tabular}

Begrunnelsen for å ta hensyn til ulikheter i den totale helse uten behandling, ligger i det såkalte "fair innings»-argumentet om at vi har rett på det som anses å være en normal helsejustert forventet levetid (24)-(25). I tabell 2 vil slike ulikheter i $(A+P)$ trekke i retning av å prioritere person Pål. I stedet for å begrunne prioritering av Pål med at han er yngst, kunne vi henvise til at helsetapet hans er størst, m.a.o. et argument for å redusere ulikheter i helsetap. Så lenge QALE er like stor, vil argumentet for å redusere ulikheter i total helse uten behandling $(\mathrm{A}+\mathrm{P})$ logisk sett være det samme som å redusere ulikheter i helsetap. Konklusjonen blir nøyaktig den samme, spørsmålet er bare hvorvidt prioriteringen begrunnes med størst helsetap eller yngst alder.

\section{Tabell 2}

Talleksempel med ulik alder og tap, lik prognose og gevinst. QALE = helsejustert forventet levetid (quality-adjusted life expectancy)

\begin{tabular}{|lccccc|}
\hline & Alder & Prognose & Gevinst & Tap & QALE \\
\hline Pål & 30 & 1 & 1 & 43 & 75 \\
\hline Ola & 70 & 1 & 1 & 3 & 75 \\
\hline
\end{tabular}

Følgelig vil disse to ulike begrunnelsene kun ha praktisk betydning når QALE varierer. Som nevnt er det betydelig variasjon i QALE mellom grupper avhengig av kjønn, sosial posisjon og atferd. I tabell 3 er alder, prognose og gevinst like, mens helsetapene er ulike, noe som skyldes ulikheter i QALE. Årsaken til deres ulike QALE kan være at Espen og Ola tilhører ulike sosiale klasser, der Espen er den med høyest sosiale posisjon. Eller det kan skyldes kjønnsulikheter.

\section{Tabell 3}


Talleksempel med ulike tap (og QALE), alt annet likt. QALE = helsejustert forventet levetid (quality-adjusted life expectancy)

\begin{tabular}{|lccccc|}
\hline & Alder & Prognose & Gevinst & Tap & QALE \\
\hline Espen & 70 & 1 & 1 & 10 & 82 \\
\hline Ola & 70 & 1 & 1 & 3 & 75 \\
\hline
\end{tabular}

Uansett om ulikheten i QALE skyldes sosial klasse eller kjønn, vil det å ta hensyn til ulikheter i helsetap ved prioriteringer - når alt annet er likt - nettopp innebære at man opprettholder en helseulikhet. Det kontraintuitive her står i kontrast til eksemplene over, der begrunnelsen nettopp var å redusere helseulikheter.

\section{Noe for Språkrådet eller Prioriteringsrådet?}

Det første budskapet i denne artikkelen er av ren semantisk karakter, nemlig hva meningsinnholdet i et begrep er. Kanskje bør vi overlate dette til Språkrådet? Om ikke det vil gi et entydig råd, kan vi i stedet gjøre en spørreundersøkelse for å finne hvilken av de fire forståelsene som er mest utbredt blant leg og lærd.

Det andre budskapet er for Prioriteringsrådet, som bør avklare hvilke helsemengder som er prioriteringsrelevante: Ønsker man å ta hensyn til ulikheter i prognosen uten behandling, ulikheter i alder, eller mener man at ulikheter i helsetap har selvstendig relevans uavhengig av alder og prognose?

Et tredje budskap vil være til Forskningsrådet, som bør finansiere empiriske studier som vil finne ut av hvilke helsemengder folk mener beslutningstakere bør tillegge størst vekt ved prioriteringer.

\section{LITTERATUR}

1. Norges offentlige utredninger. Retningslinjer for prioriteringer innen norsk helsetjeneste. NOU 1987: 23 .

2. Helsedirektoratet. Prioriteringer i helsesektoren: Verdigrunnlag, status og utfordringer. Oslo: Helsedirektoratet, 2012. www.helsedirektoratet.no/publikasjoner/prioriteringer-ihelsesektoren/Sider/default.aspx (20.11.2012).

3. Helsedirektoratet. Samfunnsøkonomiske analyser i helsesektoren - en veileder. Oslo: Helsedirektoratet, 2011. www.helsedirektoratet.no/finansiering/samfunnsokonomiskeanalyser/veiledere/Sider/samfunnsokonomiske-analyser-i-helsesektoren.aspx (20.11.2012).

4. WHO. Health data and statistics. www.who.int/healthinfo/statistics/en/(10.5.2012).

5. Nord E. The trade-off between severity of illness and treatment effect in cost-value analysis of health care. Health Policy 1993; 24: 227-38. [PubMed] [CrossRef]

6. Nord E. Towards cost-value analysis in health care? Health Care Anal 1999; 7:167-75. [PubMed]

7. Schwappach DLB. Resource allocation, social values and the QALY: a review of the debate and empirical evidence. Health Expect 2002; 5: 210-22. [PubMed] [CrossRef]

8. Jacobsson F, Carstensen J, Borgquist L. Caring externalities in health economic evaluation: how are they related to severity of illness? Health Policy 2005; 73: 172-82. [PubMed] [CrossRef]

9. Shah KK. Severity of illness and priority setting in healthcare: a review of the literature. Health Policy 2009; 93: 77-84. [PubMed] [CrossRef]

10. Richardson JR, McKie J, Peacock SJ et al. Severity as an independent determinant of the social value of a health service. Eur J Health Econ 2011; 12: 163-74. [PubMed] [CrossRef]

11. Lancsar E, Wildman J, Donaldson C et al. Deriving distributional weights for QALYs through discrete choice experiments. J Health Econ 2011;30: 466-78. [PubMed] [CrossRef] 
12. Nord E. Veiledende verditall for kostnad-nytte-analyser av helsetjenester. Tidsskr Nor Lægeforen 1996; 116:3246-9. [PubMed]

13. Hansson LF, Norheim OF, Ruyter KW. Equality, explicitness, severity, and rigidity: the Oregon plan evaluated from a Scandinavian perspective. J Med Philos 1994; 19:343-66. [PubMed]

14. Defechereux T, Paolucci F, Mirelman A et al. Health care priority setting in Norway a multicriteria decision analysis. BMC Health Serv Res 2012; 12:39. [PubMed] [CrossRef]

15. Norheim OF. Clinical priority setting. BMJ 2008; 337: a1846. [PubMed] [CrossRef]

16. Olsen JA. Theories of justice and their implications for priority setting in health care. J Health Econ 1997; 16: 625-39. [PubMed] [CrossRef]

17. Cookson R, McCabe C, Tsuchiya A. Public healthcare resource allocation and the Rule of Rescue. J Med Ethics 2008; 34:540-4. [PubMed] [CrossRef]

18. Kapiriri L, Arnesen T, Norheim OF. Is cost-effectiveness analysis preferred to severity of disease as the main guiding principle in priority setting in resource poor settings? The case of Uganda. Cost Eff Resour Alloc 2004; 2: 1. [PubMed] [CrossRef]

19. NICE. Appraising life-extending, end of life treatments. www.nice.org.uk/media/E4A/79/SupplementaryAdviceTACEoL.pdf(10.5.2012).

20. Rawlins M, Barnett D, Stevens A. Pharmacoeconomics: NICE’s approach to decision-making. $\mathrm{Br}$ J Clin Pharmacol 2010; 70:346-9. [PubMed] [CrossRef]

21. Dolan PA, Olsen JA. Equity in health: the importance of different health streams. J Health Econ 2001; 20: 823-34. [PubMed] [CrossRef]

22. Rawls J. A theory of justice. Oxford: Oxford University Press, 1971.

23. Hadorn DC. Setting health care priorities in Oregon: Cost effectiveness meets the rule of rescue. JAMA 1991; 268: 2218-25 . [CrossRef]

24. Williams A. Intergenerational equity: an exploration of the 'fair innings' argument. Health Econ 1997; 6: 117-32. [PubMed]

25. Tsuchiya A. QALYs and ageism: philosophical theories and age weighting. Health Econ 2000; 9: 5768. [PubMed]

Publisert: 8. januar 2013. Tidsskr Nor Legeforen. DOI: 10.4045/tidsskr.12.0659

Mottatt 25.5 2012, første revisjon innsendt 18.9. 2012, godkjent 1.11. 2012. Medisinsk redaktør Petter Gjersvik.

(C) Tidsskrift for Den norske legeforening 2023. Lastet ned fra tidsskriftet.no 26. april 2023. 